\title{
Resenha
}

Psicanálise entrevista - volume 1

Mara Selaibe e Andréa Carvalho (Orgs.)

São Paulo: Estação Liberdade, 2014, 329p.

\section{PERCURSO DÁ VOZ À PSICANÁLISE}

\author{
Paula Fontana Fonseca
}

DOI: http://dx.doi.ors/10.11606/issn.1981-1624.v19i2p369-373

Ler o livro Psicanálise entrevista, organizado por Mara Selaibe e Andréa Carvalho, é literalmente percorrer um pouco da história da psicanálise e vê-la trabalhar.

São um total de dezoito entrevistados que falam em nome próprio acerca de suas teorizações e apropriações da psicanálise. Já em seu primeiro número, a revista Percurso, editada pelo Departamento de Psicanálise do Instituto Sedes Sapientiae desde 1988, contava com uma seção de entrevista. Fazendo jus, assim, ao que enunciava como sendo seu leitmotiv: fazer trabalhar os conceitos clínicos e teóricos da psicanálise possibilitando um movimento de contínua recriação.

Em seu prefácio ao livro, Renato Mezan nos conta do trabalho de selecionar e organizar as entrevistas e o efeito que sua leitura produz, o de fazer surgir um panorama fascinante da psicanálise nos últimos sessenta anos. A vastidão do material fez que as organizadoras optassem por publicá-las em dois tomos, tendo sido o volume 1 publicado em maio de 2014.

Cada entrevista é um mergulho num pensamento do autor, seus questionamentos, percurso na psicanálise. Talvez o ponto mais pregnante que perpassa o livro seja o testemunho sobre o que é ser analista. Pergunta esta que, mesmo não sendo enunciada explicitamente

Psicóloga do Serviço de Psicologia Escolar do Instituto de Psicologia da Universidade de São Paulo (IPUSP) e doutoranda pela Faculdade de Eduçação da Universidade de São Paulo (FEUSP) São Paulo, SP, Brasil. 
ao entrevistado, salta aos olhos dos leitores.

Pontalis, o primeiro entrevistado trazido no livro, alerta que não se deve, jamais, instalar-se numa posição de analista. "Devemos nos manter inquietos sobre o porvir da análise e também sobre nossa posição de analista" (p. 53). Claro que as entrevistas nos contam de muitas divergências, mas, se há uma concordância, ela seguramente assenta na inquietação presente na relação de cada um com a psicanálise.

É essa inquietação que coloca a psicanálise na cultura, e isso se dá desde Freud, como sabemos. Há uma inserção de mão dupla, estar na cultura faz a psicanálise se interrogar e, ao mesmo tempo, produz efeitos de mudança na cultura ocidental.

O debate sobre a leitura e proposição lacaniana do retorno a Freud levam-nos a viver a efervescência desse momento histórico de recriação da psicanálise. Conforme formula Emilio Rodrigué, em maio de 1968 na França "Marx morreu e Freud, ferido numa ruela da Rive Gauche, foi salvo por Lacan" (p. 179). Muitos dos entrevistados foram partícipes importantes nesse processo, notadamente Pontalis e Laplanche. As divergências ganham a cena juntamente com um debate conceitual que Laplanche sintetiza ao diferenciar a interpretação da tradução. Para ele "Lacan é um grande interpretador de Freud, mas não faz justiça" (p. 72), na medida em que não anuncia o que seria próprio à tradução: "ele disse isso e não outra coisa” (p. 72). Green, outro

370 Estilos clin., São Paulo, v. 19, n. 2, mai./ago. 2014, 369-373. 
dos entrevistados, adensa a discussão ao aprofundar as consequências que extrai da segunda tópica freudiana. Ele pontua, por exemplo, que talvez a ideia lacaniana do inconsciente estruturado como linguagem "possa ser defendida no caso da primeira tópica. Mas jamais no caso da segunda" (p. 61).

Para os que se interessam pela história da psicanálise, temos aqui um prato cheio. As versões e apreensões singulares dessa época são entremeadas com apropriações teóricas rigorosas. Cada autor faz seus destaques e os aprofunda de maneira consistente. Temos assim uma oportunidade de revisitarmos nossas leituras prévias, seja no diálogo com nossos autores de referência, seja pela crítica feita a eles.

Outro ponto constante são os mestres. Conforme ressaltam Claude Le Guen, "nossas ideias - por mais originais que sejam - são sempre emprestadas dos outros, ou pelo menos, inspiradas neles" (p. 107), e Ivone Lins, ao citar Winnicott, "é impossível ser original sem se apoiar na tradição" (p. 343).

Numa atitude de reconhecimento, vários autores, não necessariamente psicanalistas, são lembrados como referências. Nessa vasta lista temos Freud, Lacan, Klein, Bion, Winniccot com uma certa recorrência. Mas há tantos outros encontros surpreendentes, que seguimos aqui na esteira da definição oferecida por Oury ao destacar que "o caminho se faz andando e é por acaso que pode haver um encontro, mas não é obrigatório" (p. 92). Esse grande pensador, pouco traduzido para o português aliás, conta em sua belíssima entrevista sobre seu encontro com Tosquelles. Acaso no caminho do psicanalista, que o conduz a certas leituras e, no caso particular de Oury, ao encontro de La Borde em 1953.

Joyce McDougall utiliza do termo maître-à-penser, bem apropriado para abordar a relação que sobressai nas entrevistas quando Le Guen fala de Pierre Mâle; Marcelo Viñar, do casal Barangers; e Otto Kernberg, de Inácio Matte-Blanco, para ficar com apenas alguns exemplos.

Ainda nesse sentido, Silvia Alonso conta de seu percurso, de como saiu de Tucumán, na Argentina, em busca da psicanálise que lhe interessava. Fala da emoção que sente ao lembrar de sua conversa com Madre Cristina e de sua forte relação com o Sedes. "Cada analista em sua clínica é um analista singular, que trabalha em nome próprio. Isso não implica negar tudo aquilo que o precede, nem deixar de reconhecer as influências que recebeu, as filiações às quais pertence - o que é fundamental para limitar a onipotência” (p. 329).

É Joyce McDougall quem faz um alerta contundente sobre a importância de se "olhar além das muralhas da própria escola de 
pensamento à qual se pertence" (p. 127). Ela segue dizendo que essa prisão, a devoção incondicional, pode ser um obstáculo na escuta dos pacientes, especialmente "quando esses últimos não se encaixam em seu enquadre teórico” (p. 127).

O pertencimento às escolas e instituições de psicanálise aparece tanto numa referência histórica como também na intenção de problematizar a formação de analista. Essa é uma pergunta que se revela cara sobretudo aos entrevistadores que explicitam seu interesse pelo tema da transmissão da psicanálise, tendo em vista a pertinência institucional dos mesmos ao Departamento de Psicanálise do SEDES.

Kernberg, que era à época (1995) candidato a presidente da IPA, fala sobre o risco de rigidez e autoritarismo encontrado nos institutos de Psicanálise. Para ele, a "psicanálise não é uma teoria completa, acabada, fixa, sobre o humano" (p. 143). Chaim Katz é contundente a esse respeito ao abordar o totalitarismo perverso que termina por obrigar "os psicanalistas a falarem uma mesma língua" (p. 247). Nesse mesmo sentido, Joel Birman considera como consequência ao que chama "servidão à figura do líder" (p. 268) que o potencial de ousadia "fica muito esterilizado quando não se corre o risco no plano simbólico por receio de ser excluído no plano institucional" (p. 269).

Se o risco do dogmatismo aparece de forma contundente, também somos instigados pelo impulso que motiva cada entrevistado em seu enlace com a psicanálise.

Radmila Zygouris divide conosco como se sentiu confortável em meio a loucura e paixão em que, em suas palavras, estavam imersos os lacanianos. Conforme relata, sentiu que "gostava dessa gente... Compreendam, não havia ali aquela respeitabilidade burguesa" (p. 187). Para ela, "o forte de Lacan era colocar as coisas em ato" (p.189). Monique Schneider fala de seu encontro, por intermédio de Conrad Stein, com o texto essencial "A Interpretação dos Sonhos" e sua busca por "pesquisar o trajeto textual preciso", além de revelar sua preferência pelo que chama de "Freud vulcânico" (p. 212). Já Isaías Melshon discorre sobre a interlocução que faz de modo original entre psicanálise e filosofia para pensar a consciência, a representação, a estética e o tempo.

Sérgio Paulo Rouanet destaca que para Freud a psicanálise sempre foi uma “ciência do social” (p. 363). Único não analista a figurar nesse volume, ao ser perguntado sobre como se aproximou da psicanálise, conta que o fez pelo simples fato de ter feito análise. Certa vez, na análise que empreendeu em Genebra, após fazer interpretações que acreditava serem

372 Estilos clin., São Paulo, v. 19, n. 2, mai./ago. 2014, 369-373. 


\section{Resenha}

brilhantíssimas, seu analista agradeceu-o pela conferência. "Dei a maior gargalhada, e a partir desse momento minha análise começou" (p. 358).

Onde, quando, como a psicanálise nos fisga? Pergunta crucial apenas na medida em que estejamos advertidos da indicação de Marcelo Viñar quando cita "uma linda frase de Maurice Blanchot que diz que 'a resposta é a desgraça da pergunta"' (p. 227).

"A psicanálise, como outras ideias, é uma ideia boa de ser agida" (p. 309), afirma Jurandir Freire Costa. Agida mais do que respondida, poderíamos inferir... Para ele, a psicanálise daria "esse espaço de abertura da surpresa. Pois justamente o sintoma fecha esse espaço de possibilidade quando se tem a certeza sintomática" (p. 306).

São muitos os meandros, os fios e a tessitura decorrentes das entrevistas. No prefácio, Mezan convida o leitor ao prazer da leitura e a deixarse encantar pelo "pensamento livre que emana de cada página” (p. 24). Convite reiterado aqui, para que o leitor ouse lançar-se nesse percurso inquietante, que poderá tocar, ao acaso, o que lhe é mais singular em sua relação com a psicanálise.

paulaffonseca@uol.com.br Av. Prof. Mello Moraes, 1721 - Bloco D 05508-030 - São Paulo - SP - Brasil.

Recebido em maio/ 2014. Aceito em junbo/ 2014. 